\title{
The Impact of Dysphagia Therapy on Quality of Life in Patients with Parkinson's Disease as Measured by the Swallowing Quality of Life Questionnaire (SWALQOL)
}

Annelise Ayres ${ }^{1}$ Geraldo Pereira Jotz ${ }^{2}$ Carlos Roberto de Mello Rieder ${ }^{3}$

Artur Francisco Schumacher Schuh ${ }^{4}$ Maira Rozenfeld Olchik ${ }^{5}$

1 Post-Graduation Program of Health Sciences, Universidade Federal de Ciências da Saúde de Porto Alegre, RS, Brazil

2 Department of Morphological Sciences, Universidade Federal do Rio Grande do Sul, Porto Alegre, RS, Brazil

${ }^{3}$ Movement Disorders Unit, Hospital de Clínicas de Porto Alegre,

Porto Alegre, RS, Brazil

${ }^{4}$ Department of Medical Sciences, Universidade Federal do Rio Grande do Sul, Porto Alegre, RS, Brazil

${ }^{5}$ Department of Surgery and Orthopaedics, Universidade Federal do

Rio Grande do Sul, Porto Alegre, RS, Brazil

Int Arch Otorhinolaryngol 2016;20:202-206.
Address for correspondence Maira Rozenfeld Olchik, Universidade Federal do Rio Grande do Sul, Rua Ramiro Barcelos, 2492, Porto Alegre, RS, 90035-002, Brazil (e-mail: mairarozenfeld@hotmail.com).

\begin{abstract}
Keywords

- Parkinson disease

- quality of life

- deglutition disorders

- dysphagia

- rehabilitation
\end{abstract}

Introduction Dysphagia is a common symptom in Parkinson's disease (PD) and it has been associated with poor quality of life (QoL), anxiety, depression.

Objective The aim of this study was to evaluate the quality of life in individuals with PD before and after SLP therapy.

Methods The program consisted of four individual therapy sessions. Each session comprised guidelines regarding food and postural maneuvers (chin down). The Quality of Life in Swallowing Disorders (SWAL-QOL) questionnaire was applied before and after therapy.

Results The sample comprised of 10 individuals (8 men), with a mean (SD) age of 62.2 (11.3) years, mean educational attainment of 7.5 (4.3) years, and mean disease duration of 10.7 (4.7) years. Thirty percent of patients were Hoehn and Yahr (H\&Y) stage 2, 50\% were $\mathrm{H} \& \mathrm{Y}$ stage 3 , and $20 \%$ were $\mathrm{H} \& Y$ stage 4 . Mean scores for all SWAL-QOL domains increased after the intervention period, with significant pre- to post-therapy differences in total score $(p=0.033)$ and domain 4 (symptom frequency) $(p=0.025)$. There was also a bias significance for domain 5 (food selection) $(p=0.095)$.

Conclusion Patients exhibited improvement in swallowing-related quality of life after a SLP therapy program. The earlier in the course of PD, greater the improvement observed after therapy. received

November 16, 2015

accepted

February 16, 2016

published online

April 19, 2016
DOI http://dx.doi.org/

10.1055/s-0036-1582450. ISSN 1809-9777.
Copyright $(2016$ by Thieme Publicações License terms

Ltda, Rio de Janeiro, Brazil c) $(1) \$$ 


\section{Introduction}

Dysphagia is a common symptom in Parkinson's disease (PD) and may occur at any stage in the disease course. It is estimated that up to $80 \%$ of patients with early-stage PD experience oropharyngeal dysphagia. At advanced stages, the incidence may be as high as $95 \%{ }^{1-4}$ The main signs and symptoms of dysphagia in PD are: delayed oral transit; difficulties in bolus formation; residual food in the oral cavity; poor bolus ejection; multiple swallows; posterior loss of bolus; decreased swallowing reflex; alterations in vocal fold closure; reduced pharyngeal and esophageal motility; pharyngeal stasis; esophageal sphincter dysfunction; gastroesophageal reflux; laryngeal penetration; pulmonary aspiration; oropharyngeal bradykinesia; reduced anterior hyoid bone movement; and decreased epiglottis rotation angle during swallowing. ${ }^{5-7}$ Furthermore, studies show that pneumonia is the main cause of death in patients with $\mathrm{PD}$, demonstrating the importance of speech-language pathologist (SLP)-based intervention for dysphagia to delay the onset of this symptom. 8 ,9

Within this context, a growing number of studies have search to assess the efficacy and efficiency of therapeutic interventions made by SLP for this signs and symptom of dysphagia in PD, as described above. ${ }^{5,10-12}$ These studies have demonstrated the benefits of several treatment strategies in decreasing signs and symptoms of dysphagia and improving swallow safety in patients with PD, including food consistency modification, thermal-tactile stimulation, and expiratory muscle strength training (EMST). ${ }^{5,10-12}$

According to literature, ${ }^{6,13,14}$ patients with PD scored lower in the SWAL-QOL survey, suggesting poor quality of life. Furthermore, patients with more advanced disease scored lower on the questionnaire. Thus, dysphagia has been associated with poor quality of life (QoL), anxiety, depression.

In the revised literature, we observed an absence of national studies that ascertain the impact on QoL of SLPbased intervention. Within this context, the present study assess QoL in patients with PD before and after a speechlanguage pathologist-led dysphagia therapy program.

\section{Methods}

This is a case-control study with subjects with Parkinson's disease. We selected participants from the Movement Disorders Center at a reference hospital. The study received approval from the Research Ethics Committee, registered under number 140263. All subjects signed an informed consent.

The inclusion criteria were a confirmed diagnosis of PD and accept to take part of a therapy program involving one session a week, during four consecutive weeks. The exclusion criteria were patients with language and/or hearing impairments that would prevent comprehension of the intervention program and patients with dementia.

Before and after therapy, patients underwent assessments which included the application of the SWAL-QOL tool. This questionnaire comprises 44 items that assess 11 domains (Burden; Eating desire; Feeding duration; Symptom frequency; Food selection; Communication; Fear; Mental health; Social Function; Sleep; and Fatigue), which are scored on a scale of 0 to 100 . It is designed to ascertain the symptoms experienced by patients and the influence of these symptoms on QoL. The SWAL-QOL is an important tool for monitoring the efficacy of rehabilitation from the patient's point of view by assessing swallowing-related QoL. We used the Brazilian Portuguese validated version of the questionnaire. ${ }^{15}$

The questionnaire was administered in an examining room and had an average duration of 20 minutes. The investigator read the items and answer choices to each patient, to minimize the effect of low education level and the decrease in visual acuity, thus, ensuring a proper understanding of the questionnaire and minimizing misleading answers due to the lack of understanding of the questionnaire. To avoid possible bias, we followed this procedure with all individuals. Data collection took place from March to August 2014.

Patients took part in a SLP intervention program, which consisted of four individual therapy sessions with 30 minute each, during which patients received guidelines regarding food (-Table 1) and a postural maneuver (chin down). The chin-down posture maneuver follows the recommendations in the literature due to be easy to learn for the patient, as well as its aim of reducing the early escape and possible food intake in the airway. ${ }^{16-18}$

For statistical analysis, we conducted the Shapiro-Wilks test to verify normality of the variables. The Wilcoxon test was used to compare mean scores for each SWAL-QOL domain before and after therapy (variables without asymmetry distribution). The paired-samples Student $t$-test was used for comparison of total SWAL-QOL scores before and after therapy (variables with normal distribution). Spearman correlation coefficients were used to correlate pre- and posttherapy differences in each SWAL-QOL domain with the variables age, Hoehn and Yahr (H\&Y) stage, and educational level (variables without normal distribution). We used the Mann-Whitney Test to correlate pre- and post-therapy differences in each SWAL-QOL domain with the variable gender. Analysis of covariance was used for analysis of total SWALQOL scores in relation to the variables gender, age, and H\&Y stage. We assumed a $5 \%$ error rate for all tests. We performed all analyses in SPSS 20.0.

\section{Results}

The study sample comprised 11 patients with PD. However, one patient was excluded for failure to take part in all sessions. The final sample comprised 10 participants. Of these, $80 \%$ were male. The mean (SD) age was $62.2( \pm 11.3)$ years, the mean educational level was 7.5 (4.3) years, and the mean disease duration was 10.7 (4.7) years. Regarding disease stage, three patients (30\%) were H\&Y stage 2, five patients (50\%) were H\&Y 3, and two patients (20\%) were H\&Y 4.

- Table 2 shows comparisons of scores for each SWAL-QOL domain before and after the SLP therapy. The mean of all 
204 Dysphagia Therapy on QoL in Patients with Parkinson's Disease Measured by SWALQOL Ayres et al.

Table 1 Guidelines regarding food

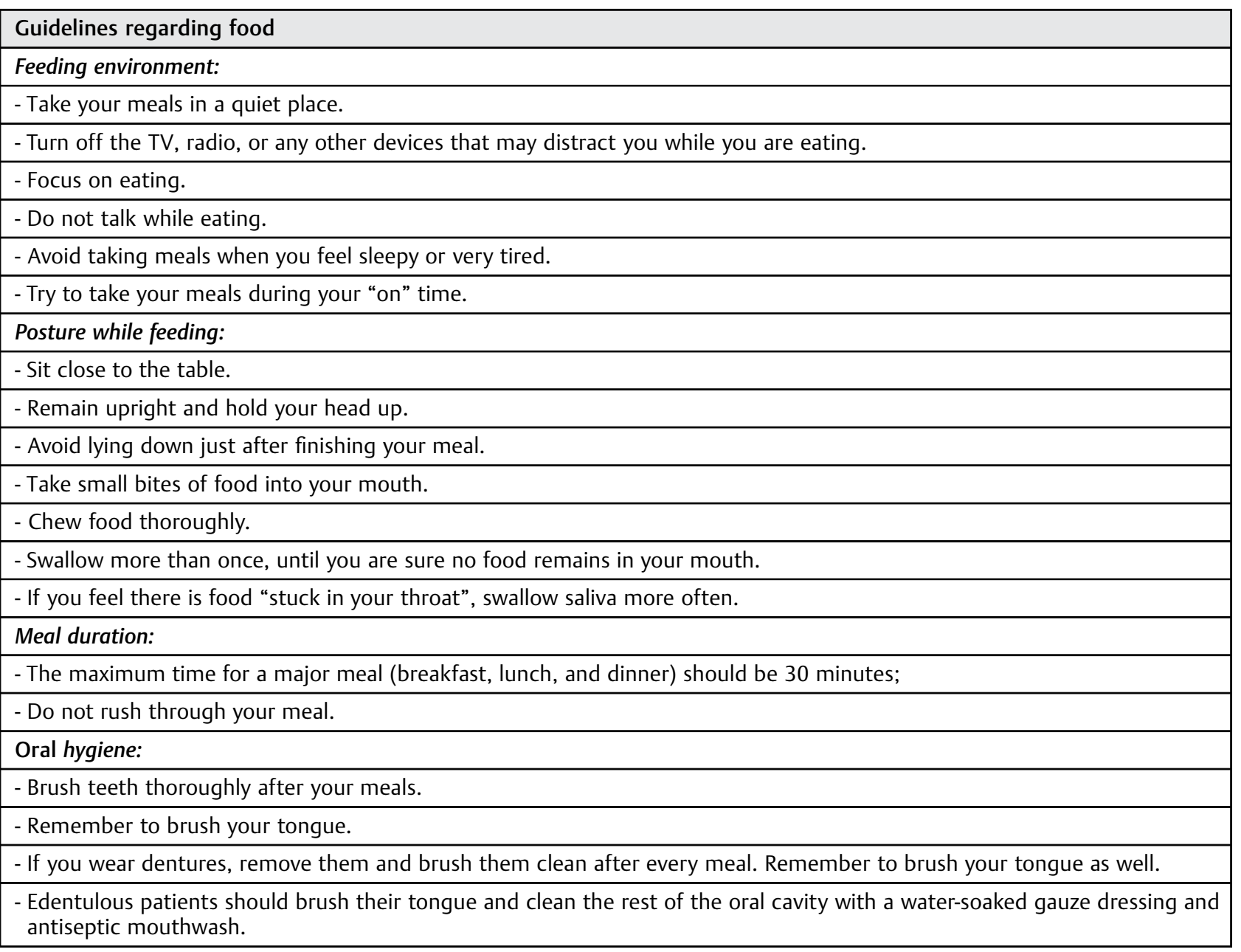

Table 2 SWAL-QOL scores before and after Dysphagia therapy

\begin{tabular}{|l|l|l|l|l|l|l|}
\hline \multirow{2}{*}{ SWAL-QOL Domain } & \multicolumn{2}{l|}{ PRE } & POST & \multirow{2}{*}{ U $^{\text {w }}$} \\
\cline { 2 - 5 } & Mean & SD & Mean & SD & \\
\hline 1. Burden & 77.5 & \pm 14.44 & 82.5 & \pm 30.73 & 0.258 & -1.131 \\
\hline 2. Eating desire & 79.15 & \pm 19.35 & 82.49 & \pm 24.67 & 0.527 & -0.632 \\
\hline 3. Feeding duration & 52.5 & \pm 39.87 & 58.75 & \pm 36.82 & 0.833 & -0.211 \\
\hline 4. Symptom frequency & 69.61 & \pm 10.82 & 79.42 & \pm 14.97 & $0.025^{*}$ & -2.244 \\
\hline 5. Food selection & 65 & \pm 26.87 & 86.25 & \pm 28.53 & 0.095 & -1.667 \\
\hline 6. Communication & 42.5 & \pm 23.71 & 55 & \pm 31.84 & 0.103 & -1.630 \\
\hline 7. Fear & 66.87 & \pm 25.69 & 76.87 & \pm 29.47 & 0.260 & -1.127 \\
\hline 8. Mental health & 80.5 & \pm 22.04 & 84 & \pm 26.64 & 0.752 & -0.315 \\
\hline 9. Social Function & 71 & \pm 28.06 & 83 & \pm 26.58 & 0.116 & -1.572 \\
\hline 10. Sleep & 31.25 & \pm 38.75 & 46.25 & \pm 39.10 & 0.176 & -1.355 \\
\hline 11. Fatigue & 70.8 & \pm 27.28 & 83.31 & \pm 17.58 & 0.123 & -1.544 \\
\hline Total** & 64.24 & \pm 29.65 & 74.34 & \pm 30.49 & $0.033^{*}$ & 0.672 \\
\hline
\end{tabular}


Dysphagia Therapy on QoL in Patients with Parkinson's Disease Measured by SWALQOL Ayres et al. 205

Table 3 Correlations of SWAL-QOL Domains with Gender, H\&Y stage, age, and educational level

\begin{tabular}{|c|c|c|c|c|c|c|c|}
\hline \multirow[t]{2}{*}{ SWAL-QOL Domain } & \multirow[t]{2}{*}{ Gender $^{a}$} & \multicolumn{2}{|l|}{$\mathrm{H} \& \mathrm{Y}$} & \multicolumn{2}{|l|}{ Age } & \multicolumn{2}{|c|}{ Education } \\
\hline & & $p$ & $r$ & $p$ & $r$ & $p$ & $r$ \\
\hline 1. Burden & 0.506 & 0.203 & 0.469 & 1.0 & 0.000 & 0.772 & 0.106 \\
\hline 2. Eating desire & 0.224 & 0.792 & 0.103 & 0.627 & -0.176 & 0.174 & 0.467 \\
\hline 3. Feeding duration & 0.895 & 0.396 & -0.323 & 0.407 & -0.295 & 0.892 & -0.050 \\
\hline 4. Symptom frequency & 0.433 & 0.646 & -0.178 & 0.365 & -0.321 & 0.464 & 0.262 \\
\hline 5. Food selection & 0.694 & $0.051^{*}$ & 0.665 & 0.542 & 0.220 & 0.331 & 0.344 \\
\hline 6. Communication & 0.143 & 0.807 & -0.096 & 0.892 & 0.049 & 0.523 & -0.230 \\
\hline 7. Fear & 0.147 & 0.560 & -0.226 & 0.134 & -0.508 & 0.086 & 0.569 \\
\hline 8. Mental health & 0.589 & 0.709 & 0.146 & 0.519 & -0.232 & 0.089 & 0.565 \\
\hline 9. Social Function & 0.893 & 0.444 & 0.293 & 0.379 & 0.313 & 0.890 & 0.050 \\
\hline 10. Sleep & $0.047^{*}$ & $0.024^{*}$ & -0.743 & 0.320 & -0.351 & 0.993 & 0.003 \\
\hline 11. Fatigue & 0.147 & 0.773 & 0.113 & 0.324 & -0.177 & 0.358 & 0.326 \\
\hline Total $^{* *}$ & 0.554 & 0.858 & - & 0.936 & - & 0.543 & - \\
\hline
\end{tabular}

SWAL-QOL domains increased after the SLP intervention period. However, the difference was only significant for the Symptom Frequency domain $(p=0.025$ and $r=-2.24)$. In addition, a significant difference in total scores was observed after therapy ( $p=0.033)$.

The mean scores for each SWAL-QOL domain before and after therapy were then tested for correlation with the variables gender, H\&Y stage, age and educational level, as shown in -Table 3. A significant correlation of domain Sleep was observed with gender $(p=0.047)$ and H\&Y stage $(p=0.024$ and $r=-0.74)$. Furthermore, the Food Selection domain correlated significantly with H\&Y stage $(p=0.051$ and $r=0.66$ ). In this way, the earlier stage of PD, the better the improvement experienced in QoL after therapy.

In the assessment of swallowing, with regards to the signs and symptoms of dysphagia, there was a significant reduction after SLP therapy for both consistencies, solid $(p<0.001)$ and liquid $(p=0.022)$.

\section{Discussion}

Although the literature ${ }^{1,2}$ reports the high incidence of dysphagia in patients with $\mathrm{PD},{ }^{1,2}$ the influence of dysphagia as a leading cause of death in $\mathrm{PD},{ }^{8,9}$ the silent aspiration which reduces complaints, ${ }^{19}$ and its negative impact in QoL, ${ }^{13,20}$ there are still great difficulties in conducting studies with rehabilitation. This is due to the absence of patient complaints, ${ }^{17}$ and the difficulties of movement in patients with PD, caused by postural instability, a characteristic symptom of PD. These factors mean that few patients agree to participate in this type of study, decreasing adherence to the therapeutic process. In addition, SLP therapy is a continuous process, which can be impaired due to clinical fluctuations of the patient, such as worsening of motor symptoms.

Thus, few studies have investigated the influence of therapy on swallowing-related QoL. In the literature review for this article, we found only three studies, ${ }^{6,10,14}$ all of which reported QoL and clinical improvement after SLP intervention, regardless of the therapeutic technique used and the number of sessions.

Data analysis showed that average scores for all SWAL-QOL domains improved after the intervention period. However, this difference was only significant for the Symptom Frequency domain, providing evidence of a positive modification in QoL regarding the frequency of symptoms. These findings corroborate with the literature. ${ }^{6,14}$ In addition, there is a positive change in the complaints, due to reduction in the frequency of symptoms presented by the patients. Corroborating with Argolo et al, ${ }^{6}$ which found significant improvement in Fear and Frequency of Symptoms domains.

In this study, we verified that the relation between QOL and swallowing was moderate in the first assessment before the therapy program, showing that dysphagia had a negative effect on patient QoL. According to the study by PlowmanPrine et $\mathrm{al}^{20} 36$ patients with and without dysphagia, with a mean age 65.6 years $( \pm 10.8)$ and disease duration 11.5 years $( \pm 0.5)$, and similar to our findings, patients with PD evaluated by SWAL-QOL exhibited moderate swallow-related QoL. In addition, dysphagia had a negative impact on patient QoL; total scores in the dysphagia group were lower than in the non-dysphagia group.

Regarding swallowing-related complaints, the study found positive impacts on QoL regardless of age, educational level, or H\&Y score; Disease stage was the only variable to interfere with QoL. This corroborates with the existing literature, ${ }^{6}$ which reports a reduction in swallow-related complaints after SLP intervention. However, in both studies, the sample can be a limiting factor, due to the significantly small sample size of 10 patients in this study and 15 patients in the literature. The limited sample size in the present study was due to the difficulty of conducting a study therapy in PD individuals.

Thus, it is important to note the importance of dysphagia therapy for this population, to reduce the complaints regarding swallowing and provide an improvement in QoL of these 
patients. We verified that the therapeutic strategies used in both studies are distinct, and yet the results resemble each other. This finding suggests that SLP therapy regarding the increased attention given to the feeding problem by the patient may be the deciding factor for the success of the therapeutic process. This is due the fact that silent aspiration is a frequent clinical sign of dysphagia in patients with PD. It is known that the absence of the cough reflex limits the possibility of dysphagia identification, which can cause a decrease in the complaint and awareness of the problem by patients. $^{21,22}$

This finding demonstrates the importance of dysphagia therapy in this population, as a way of reducing swallowingrelated complaints and improving QoL.

Our sample was predominantly composed by males, with mean age of $62.2( \pm 11.3)$ years, as in the previous studies of Plowman-Prine et $\mathrm{al}^{20}$ and Argolo et $\mathrm{al}^{6}{ }^{6}$ in which the mean age was \pm 65.6 and \pm 59.2 years, respectively. According to the literature men have a higher estimated risk of developing PD than women. ${ }^{23}$

Although the intervention applied in the present study consisted of only four weekly sessions of therapy, versus five weekly sessions in the Argolo et $\mathrm{al}^{6}$ study and 13 to 15 sessions in the Heijen et $\mathrm{al}^{14}$ study, we observed similar outcomes in terms of QoL improvement. Therefore, the number of therapy sessions does not seem to be a factor of direct influence on the improvement of QOL in this population. Furthermore, in studies from Troche et al, ${ }^{10}$ Argolo et $\mathrm{al}^{6}$ and Heijen et al, $^{14}$ it was not used the same therapeutic strategy, and yet, it was found in all studies a improvement of QOL in the patients. Tis way, it also verifies the diversity of SLP treatment strategies for improvement of QOL related to swallowing, in individuals with PD.

\section{Conclusion}

Our results suggest that swallowing-related QoL improved after a SLP intervention. The early stage of PD, the greater the improvement experienced after therapy. This demonstrates that the earlier start SLP intervention better will be the effects on quality of life. We observed positive modifications in dysphagia-related complaints regardless of gender, age, educational level, and H\&Y stage. Thus, disease stage was the only variable found to interfere with QoL.

\section{References}

1 Wintzen AR, Badrising UA, Roos RAC, Vielvoye J, Liauw L, Pauwels EKJ. Dysphagia in ambulant patients with Parkinson's disease: common, not dangerous. Can J Neurol Sci 1994;21(1):53-56

2 Nagaya M, Kachi T, Yamada T, Igata A. Videofluorographic study of swallowing in Parkinson's disease. Dysphagia 1998;13(2):95-100

3 Potulska A, Friedman A, Królicki L, Spychala A. Swallowing disorders in Parkinson's disease. Parkinsonism Relat Disord 2003;9(6):349-353

4 Kalf JG, de Swart BJ, Bloem BR, Munneke M. Prevalence of oropharyngeal dysphagia in Parkinson's disease: a meta-analysis. Parkinsonism Relat Disord 2012;18(4):311-315
5 Smith SK, Roddam H, Sheldrick H. Rehabilitation or compensation: time for a fresh perspective on speech and language therapy for dysphagia and Parkinson's disease? Int J Lang Commun Disord 2012;47(4):351-364

6 Argolo N, Sampaio M, Pinho P, Melo A, Nóbrega AC. Swallowing disorders in Parkinson's disease: impact of lingual pumping. Int J Lang Commun Disord 2015;50(5):659-664

7 Kim YH, Oh BM, Jung IY, Lee JC, Lee GJ, Han TR. Spatiotemporal characteristics of swallowing in Parkinson's disease. Laryngoscope 2015;125(2):389-395

8 Pinter B, Diem-Zangerl A, Wenning GK, et al. Mortality in Parkinson's disease: a 38-year follow-up study. Mov Disord 2015;30(2): 266-269

9 Macleod AD, Taylor KS, Counsell CE. Mortality in Parkinson's disease: a systematic review and meta-analysis. Mov Disord 2014;29(13):1615-1622

10 Troche MS, Sapienza CM, Rosenbek JC. Effects of bolus consistency on timing and safety of swallow in patients with Parkinson's disease. Dysphagia 2008;23(1):26-32

11 Pitts T, Bolser D, Rosenbek J, Troche M, Okun MS, Sapienza C. Impact of expiratory muscle strength training on voluntary cough and swallow function in Parkinson disease. Chest 2009;135(5): 1301-1308

12 Regan J, Walshe M, Tobin WO. Immediate effects of thermal-tactile stimulation on timing of swallow in idiopathic Parkinson's disease. Dysphagia 2010;25(3):207-215

13 Leow LP, Huckabee ML, Anderson T, Beckert L. The impact of dysphagia on quality of life in ageing and Parkinson's disease as measured by the swallowing quality of life (SWAL-QOL) questionnaire. Dysphagia 2010;25(3):216-220

14 Heijnen BJ, Speyer R, Baijens LWJ, Bogaardt HCA. Neuromuscular electrical stimulation versus traditional therapy in patients with Parkinson's disease and oropharyngeal dysphagia: effects on quality of life. Dysphagia 2012;27(3):336-345

15 Portas JG. Validação para a língua portuguesa-brasileira dos questionários: qualidade de vida em disfagia (Swal-qol) e satisfação do paciente e qualidade do cuidado no tratamento da disfagia (Swal-care). [dissertation]. São Paulo: Fundação Antônio Prudente, em São Paulo, Programa de Pós-graduação em Oncologia;2009

16 Logemann JA. The dysphagia diagnostic procedure as a treatment efficacy trial. Clin Commun Disord 1993;3(4):1-10

17 Logemann JA, Gensler G, Robbins J, et al. A randomized study of three interventions for aspiration of thin liquids in patients with dementia or Parkinson's disease. J Speech Lang Hear Res 2008; 51(1):173-183

18 Luchesi KF, Kitamura S, Mourão LF. Dysphagia progression and swallowing management in Parkinson's disease: an observational study. Braz J Otorhinolaryngol 2015;81(1):24-30

19 Monteiro L, Souza-Machado A, Pinho P, Sampaio M, Nóbrega AC, Melo A. Swallowing impairment and pulmonary dysfunction in Parkinson's disease: the silent threats. J Neurol Sci 2014;339(1-2): 149-152

20 Plowman-Prine EK, Sapienza CM, Okun MS, et al. The relationship between quality of life and swallowing in Parkinson's disease. Mov Disord 2009;24(9):1352-1358

21 Gasparim AZ, Jurkiewicz AL, Marques JM, Santos RS, Marcelino PCO, Junior FH. Deglutição e Tosse nos Diferentes Graus da Doença de Parkinson. Arq Int Otorrinolaringol 2011;15(2): 181-188

22 Angelis EC. Doença de Parkinson. In: Jotz GP, Angelis EC, Barros APB, ed. Tratado da Deglutição e Disfagia - No adulto e na criança. Rio de Janeiro: Revinter; 2009:274-278

23 Elbaz A, Bower JH, Maraganore DM, et al. Risk tables for parkinsonism and Parkinson's disease. J Clin Epidemiol 2002;55(1): $25-31$ 